\title{
Transformational instructor-leadership and academic performance: A moderated mediation model of student engagement and structural distance
}

Corresponding Author:

Dr. Paul T. Balwant

Affiliation: The University of the West Indies

Postal address: Department of Management Studies, UWI, St. Augustine, Trinidad

Telephone number: 8687921600

Email address: paul.balwant@sta.uwi.edu

http://orcid.org/0000-0002-0012-1545

Other Authors:

Dr. Kamal Birdi

Affiliation: The University of Sheffield

Postal address: Management School, The University of Sheffield, Sheffield, UK

Telephone number: $+44(0) 1142223288$

Email address: K.Birdi@ sheffield.ac.uk

Prof. Ute Stephan

Affiliation: Aston University

Postal address: Aston Business School, Aston University, Birmingham, UK

Telephone number: +44(0)1212043183

Email address: u.stephan@aston.ac.uk

Dr. Anna Topakas 
Affiliation: The University of Sheffield

Postal address: Management School, The University of Sheffield, Sheffield, UK

Telephone number: +44 (0)1142223240

Email address: A.Topakas@ Sheffield.ac.uk

Addresses where work was carried out:

- Institute of Work Psychology, Management School, The University of Sheffield, Sheffield, UK

- Department of Management Studies, The University of the West Indies, St. Augustine, Trinidad

DOI: 10.1080/0309877X.2017.1420149 


\title{
Transformational instructor-leadership and academic performance: A moderated mediation model of student engagement and structural distance
}

\author{
Abstract \\ Researchers are becoming increasingly interested in the use of transformational leadership \\ theory in higher education teaching (often referred to as transformational instructor- \\ leadership). Much of this body of research investigates a direct association between \\ transformational instructor-leadership and student outcomes. In the present study, we take a \\ step further by investigating (a) student engagement as a mechanism in the relationship \\ between transformational instructor-leadership and students' academic performance and \\ (b) structural distance as a moderator of the relationship between transformational \\ instructor-leadership and student engagement. Using a sample of 183 students across the \\ UK, the findings supported student engagement as a full mediator, but did not support \\ structural distance as a moderator. This study contributes to theory by (a) showing a key \\ underlying process through which transformational instructor-leadership is related to \\ students' academic performance and (b) empirically examining all three dimensions of \\ student engagement. Limitations, suggestions for future research, and practical \\ implications are discussed.
}

Keywords: Leadership, student engagement, academic performance, transformational leadership; structural distance. 


\section{Introduction}

The most central theme of leadership is that of 'influence'. Yukl (2006) examined numerous leadership definitions and explained that leadership is a process of intentional influence of one person over others to direct them towards a goal. Leadership researchers have examined this influence process in various contexts, e.g., corporations, military, politics, education, etc. In the education context, various individuals can be described as leaders including principals, curriculum developers, school administrators, teachers/instructors, etc. For instructors as leaders, researchers have largely focused on instructors occupying administrative roles and/or roles involving decision making about schools (Silva, Gimbert, and Nolan 2000). To a lesser extent, researchers have investigated instructors as leaders of their students, often referred to as instructor-leadership.

Instructor-leadership can be defined as 'a process whereby instructors exert intentional influence over students to guide, structure, and facilitate activities and relationships' (Balwant 2016, 21). In this view, instructors can lead students via mentoring, supervision of research projects, classroom teaching, etc. Of these, the most commonly studied instructor-student relationship is that of instructors teaching students for a module ${ }^{1}$. The application of leadership theories to instructor-student interactions in higher education modules is a concept that was explored primarily by organisational behaviour (e.g., Baba and Ace 1989; Dawson, Messe, and Phillips 1972; Harvey, Royal, and Stout 2003; Ojode, Walumbwa, and Kuchinke 1999; Pounder 2008; Walumbwa, Wu, and Ojode 2004) and educational researchers (e.g., Bolkan and Goodboy 2009; Gill et al. 2010).

\footnotetext{
${ }^{1}$ To describe a unit of teaching over an academic term, 'module' is used in the UK, whereas 'course' is used in the US. Because the present study is conducted in the UK, we use the term 'module' throughout the present paper.
} 


\section{Transformational leadership}

Most studies of instructor-leadership in the higher education module context (hereafter simply referred to as instructor-leadership) examine the usefulness of transformational leadership for teaching practice (for a review, see Balwant 2016). A transformational leader is defined as one who 'articulates a realistic vision of the future that can be shared, stimulates subordinates intellectually, and pays attention to the differences among the subordinates' (Yammarino and Bass 1988, 2). Adapting this definition to the higher education module context, we define a transformational instructor-leader as one who guides students towards a module's learning objectives, stimulates students intellectually, and pays attention to the differences between students.

A key difference between the corporate and higher education module definitions of transformational leadership is that the leader's vision or goal in the module context may not be 'shared' to the same degree as in the corporate context. For instance, in the corporate context, followers adopt a shared vision and coordinate and direct their efforts toward achieving goals towards this vision for both their own as well as the communal benefit. In contrast, in the module context, one student making progress on an objective is unlikely to influence other students' or the cohort's progress against the module's objectives. Nonetheless, a shared goal between instructor and student with regards to learning or academic achievement is likely to exist (Peters 2014). That is, students may strive for good grades for the prestige that is associated with good grades, career reasons, increased satisfaction, and so on. At the same time, instructors may be concerned with good grades because this visible indicator of class performance is often a gauge for teaching effectiveness and quality, thus affecting promotional prospects. Hence, the transformational leadership principle of a shared vision or objective is perhaps only partially applicable to the higher education module context. 
The foundations of transformational leadership theory were developed by Bass (1985; 1990a), who described a transformational leader in terms of four dimensions. First, charisma usually describes behaviours that are exceptionally expressive, articulate, and persuasive (Jacquart and Antonakis 2015). Charismatic behaviours also involve the use of impression management skills and image-building techniques (Conger and Kanungo 1987; House 1976). Second, inspirational motivation entails communicating an appealing vision, providing challenging standards, talking with enthusiasm and optimism, and using symbols to focus followers' efforts (Bass 1990a; Yukl 2006). Third, individualised consideration involves treating followers as unique individuals, giving specialised attention to followers' needs, lending support, and providing encouragement (Bass 1990a; Yukl 2006). Finally, intellectual stimulation describes leaders who challenge followers' ways of thinking and help them to analyse various solutions and strategies in order to tackle problems (Bass 1990a; Yukl 2006).

Evidence from a growing body of research supports the notion that transformational leaders can be effective in the higher education module context. In a meta-analytic review of transformational instructor-leadership, Balwant (2016) showed that such leadership is positively associated with student outcomes such as motivation, perceived instructor credibility, satisfaction with instructor, affect towards module, and academic performance (i.e., grades). Generally, transformational instructor-leadership research focuses primarily on direct associations between such leadership and student outcomes, without investigating the mechanisms underlying these associations. Accordingly, Balwant (2016) has called for researchers to build theory in the transformational instructor-leadership domain of research by addressing the 'why' in the relationship between transformational instructor-leadership and student outcomes such as academic performance. Therefore, the first aim of the present study is to extend transformational 
instructor-leadership research by investigating student engagement as a mechanism in the relationship between such leadership and students' academic performance.

\section{Student engagement}

Student engagement has received much attention in the educational literature (for a review, see Trowler and Trowler 2010). Unfortunately, student engagement is an ambiguous concept, and has been broadly defined in the educational literature as any form of students' involvement in their learning (for more on the ambiguity surrounding the concept of student engagement in the educational literature, see Kahu 2013; Fredricks, Blumenfeld, and Paris 2004; Balwant 2017b). Fredricks et al. (2004) state that while there is a practical benefit to engagement being a broad umbrella concept, 'it suffers from being everything to everybody' (84).

A broad definition is not inherently problematic, but it must be precise (i.e., identify the wide variety of things that it encompasses) and consistent between studies. Unfortunately, student engagement has not been consistently defined, and thus measurement of student engagement tends to vary considerably between studies. For instance, student engagement has been measured by some combination of perceptions of academic challenge, learning with peers, experiences with faculty, campus environment, participation, motivation, grades, self-efficacy, and more (Kezar and Kinzie 2006; Jimerson, Campos, and Greif 2003).

To address the lack of consistency between studies, educational researchers such as Kahu (2013) and Fredricks et al. (2004) suggest that the psychological perspective of student engagement be adopted. The psychological perspective of student engagement states that engagement is 'an individual psychological state with three dimensions ... of aff ect, cognition, and behaviour' (Kahu 2013, 764). The psychological perspective of student engagement identifies the dimensions of student engagement, but still does not define what it means for 
students to be engaged. To address this issue, Balwant (2017b) suggests that the psychological perspective be integrated with (a) Nystrand and Gamoran's (1991) concept of substantive student engagement and (b) organisational behaviour researchers' conceptualisation of work engagement.

Accordingly, Balwant (2017b) defines student engagement as 'highly activated and pleasurable emotional, behavioural, and cognitive involvement in academic activities' (7). Emotional engagement means that students experience activated and pleasurable emotions and feelings, e.g., enthusiasm or excitement. Behavioural engagement means that students exert highly activated actions, e.g., exerting extra effort or energy. Cognitive engagement means that students are fully absorbed and focused in a module, e.g., paying attention to the instructor or concentrating in class (Balwant 2017b). All three student engagement dimensions are characterised by a highly activated and positive state. We adopt Balwant's (2017b) conceptualisation of student engagement because it (1) clearly defines the meaning of engagement, (2) highlights the three dimensions from the psychological perspective, and (3) seems to be gaining consensus in recent research, thus creating consistency between student engagement studies (e.g., Burch et al. 2015; Burch, Burch, and Womble 2017; Tews et al. 2015).

\section{Transformational instructor-leadership and student engagement}

In the organisational behaviour literature, various reasons are proposed for why transformational leadership is related to work engagement. Here, we draw parallels between the work and higher education module contexts in order to explain why transformational leadership should not only influence work engagement but also student engagement. First, Vincent-Höper, Muser, and Janneck (2012) explain that transformational leaders can increase work engagement by helping their followers to realise their potential, thus satisfying higher order needs. Similarly, 
transformational instructor-leaders can influence student engagement by helping students realise their potential in terms of learning and development, and by extension enhancing their professional confidence and employability. Second, Kopperud, Martisen, and Humborstad (2014) explain that transformational leaders influence work engagement through the process of mood contagion. These leaders express positive emotions that can spread to their followers. The leaders' followers may then become more emotionally engaged in their interactions with other followers (Bono et al. 2007). In a classroom setting, the enthusiasm of a transformational instructor can inspire positive emotions among students, and thus boost their engagement. Third, Kopperud et al. (2014) explain that the challenge provided by transformational leaders can promote work engagement when that challenge is perceived as positive. Perhaps these types of challenges stimulate or activate followers in their work/study role. This premise can be translated directly to the classroom setting because instructors routinely set challenges for students in order to facilitate their learning and development, encourage their engagement, and often for purposes of formal assessment.

There is empirical support for the relationship between transformational instructorleadership and student engagement. For behavioural engagement, studies found a positive relationship between transformational instructor-leadership and facets of behavioural engagement, e.g., extra effort (Harvey, Royal, and Stout 2003; Ojode, Walumbwa, and Kuchinke 1999; Pounder 2008; Walumbwa, Wu, and Ojode 2004) and participation (Bolkan and Goodboy 2009; Harvey, Royal, and Stout 2003). For cognitive engagement, two studies showed that transformational instructor-leadership is positively related to students' retention and synthesis of module material, i.e., cognitive learning (see Bolkan and Goodboy 2009; Harrison 2011). For these two studies, the instrument used to measure cognitive learning appears to tap into 
activation, e.g., explaining the module content to other students, thinking about the module outside of class, and comparing what is learned in class to other things that the student learned.

Unlike behavioural and cognitive engagement, there is no empirical research on the relationship between transformational instructor-leadership and students' emotional engagement. One study examined the relationship between transformational instructor-leadership and student motivation in the module, and measured the latter concept using a measure which tapped into activated and pleasurable feelings such as interest and excitement (Bolkan and Goodboy 2009). However, two issues with the measure render it inappropriate for measuring engagement. First, the measure is bipolar, thus tapping into displeasure as well, e.g., uninterested and bored. Including displeasure when measuring student engagement is not conceptually sound given our earlier definition of student engagement as a pleasurable state. Second, the measure includes an item that can be indicative of behaviour, i.e., involved/uninvolved. Other studies examined the relationship between transformational instructor-leadership and students' satisfaction, but these studies operationalise satisfaction as satiation instead of high activation (e.g., Gill et al. 2010; Ojode, Walumbwa, and Kuchinke 1999; Pounder 2008; Walumbwa, Wu, and Ojode 2004). Despite the lack of studies and conclusive empirical evidence on the link between transformational instructor-leadership and emotional engagement, we argue that emotional contagion and the capacity of transformational instructor-leaders to inspire students and appeal to their emotions result in higher levels of emotional engagement among students. Hence, we expect the following: 
H1: There is a positive relationship between transformational instructor-leadership and student engagement.

\section{Student engagement and academic performance}

Student engagement is expected to influence students' academic performance because highly engaged students should effectively invest their emotional, behavioural, and cognitive resources in a module. In other words, it is plausible to expect that engaged students 'who are energetic and immersed in their studies are successful as well' (Schaufeli et al. 2002, 466). While Rich, Lepine, and Crawford (2010) examine the three dimensions of engagement in relation to performance in the organisational behaviour literature, no such study was conducted in educational research (Fredricks, Blumenfeld, and Paris 2004). Instead, educational researchers primarily examined the relationship between one or two of the three dimensions of engagement and academic performance (Fredricks, Blumenfeld, and Paris 2004).

For students' emotional engagement, few researchers examined the relationship between activated positive emotions and students' academic performance. Some of these activated positive emotions include enjoyment, pride, and hope. Enjoyment is regarded as a highly activated and optimum psychological experience (Kimiecik and Harris 1996; Pekrun et al. 2002). In a sample of university and school students, enjoyment is the most reported positive emotion followed by pride (Pekrun et al. 2002). Macey and Schneider (2008) explain that pride in one's work is characterised by pleasure and activation, and thus should be regarded as engagement. In addition to enjoyment and pride, hope is described as an emotion characterised by passion (Bruininks and Malle 2005), and thus may also be indicative of engagement. These highly activated and pleasurable emotions are likely to positively influence students' cognitive resources that can be dedicated towards task completion (Pekrun, Elliot, and Maier 2009). 
Empirical findings mostly support this argument, showing positive associations between enjoyment, pride, and hope and academic performance (Pekrun et al. 2002). However, Pekrun et al. (2009) found that, of these three activated emotions, enjoyment is not a significant predictor of academic performance. Pekrun et al. (2009) explain that perhaps, for some students, enjoyment may lead to increased efforts that facilitate improved performance, whereas, for other students, enjoyment may indicate that 'all is well' and no extra effort or preparation is needed. Pekrun et al. (2009) adds that perhaps enjoyment inhibits rote learning, which may be essential for performing well in undergraduate examinations. Even with the inconsistent findings for enjoyment, we subscribe to the notion that when students experience highly activated emotions, they should direct these emotions towards task completion, and thus perform at a high level.

For students' behavioural engagement, researchers examined the impact of participation on students' academic performance. When participation is operationalised by quality contributions in class, this can be indicative of engagement. Reinsch and Wambsganss (1994) found that when students are awarded points for quality class contributions, this leads to improvements in exam scores. The authors explain that reinforcing quality contributions influences exam scores because reinforcement encourages students to prepare more thoroughly for class. In addition to quality contributions, participation is commonly measured by attendance, and is positively related to academic performance (Plant et al. 2005; Torenbeek, Jansen, and Hofman 2010; Torenbeek, Jansen, and Suhre 2013). However, unlike the highly activated nature of quality contributions, attendance is characterised by low activation, and thus is not indicative of engagement - even though it is certainly a prerequisite for being engaged.

With regards to cognitive engagement, higher education learning requires students to be involved in their own learning. At the higher education level, students are generally given more 
freedom than at prior levels of education. External parties, e.g., instructors, parents, family, etc., are less likely to be involved in monitoring students' progress. For this reason, students' selfregulatory practices and approaches to learning become increasingly important for student success. Studies show that students' self-regulation inclusive of their approaches to learning are associated with academic performance (e.g., Heikkilä and Lonka 2006). In addition to selfregulation, cognitive engagement means that students involve themselves in their own learning by being absorbed and focused during learning events. Therefore, students are more likely to retain knowledge as well as immerse themselves in module content to a degree that allows assimilation of ideas and critical thinking. Therefore, we expect that higher levels of cognitive engagement will be accompanied by higher academic performance, and vice versa. Overall, given the arguments presented in this section, we propose the following:

H2: There is a positive relationship between student engagement and students' academic performance.

\section{Transformational instructor-leadership, student engagement, and academic performance}

Transformational leaders inspire and energise followers to perform beyond normal expectations (Bass 1990a). That is, followers are 'expected to strive for higher order outcomes' (Bass 1997, 133). By definition, transformational leaders are expected to influence followers to become highly energised or activated so that they perform beyond normal expectations. Therefore, the highly activated state of engagement should be a key mechanism through which these leaders influence followers to perform at a high level. Numerous empirical studies in organisational behaviour show that work engagement is a mechanism in the relationship between transformational leadership and employee performance (Babcock-Roberson and Strickland 2010; 
Hoon Song et al. 2012; Kopperud, Martinsen, and Humborstad 2014; Kovjanic, Schuh, and Jonas 2013; Salanova, Agut, and Peiró 2005; Vincent-Hoper, Muser, and Janneck 2012). Therefore, we expect that:

H3: Student engagement is a mechanism in the relationship between transformational instructor-leadership and students' academic performance.

\section{Structural distance as a moderator}

Leadership influence differs depending on how 'close' or 'distant' leaders and followers are from each other (Antonakis and Atwater 2002). One form of distance that can affect a leader's influence is that of structural distance. Structural distance refers to aspects of the leadership context that determine the amount of interaction that is encouraged in the leaderfollower relationship (Napier and Ferris 1993). Conceptually, structural distance has been likened to propinquity, which means nearness in place or time (Napier and Ferris 1993).

Structural distance is composed of four components including physical design (physical distance between instructor and students), opportunity to interact (social contact between instructor and student and instructors' accessibility), spatial distance (frequency of interactions between instructor and student in carrying out tasks), and span of management (number of students reporting to an instructor) (Napier and Ferris 1993). In a module context, these four components of structural distance should be reflected by class size. Specifically, the larger the size of a class, the more likely it is to be accompanied by (a) a greater physical distance between instructor and students, (b) fewer opportunities for social interactions between instructor and students, (c) fewer task contact interactions, and (d) a greater number of students reporting to an instructor. Not surprisingly, evidence suggests that larger class sizes are more distant than smaller ones (see Kendall and Schussler 2012). 
The degree to which transformational leaders influence their followers can vary according to structural distance. Specifically, transformational leadership outcomes may be contingent on the proximity of the leader and the follower (Antonakis and Atwater 2002). Bass (1990b) explains that distance deteriorates the quality of the exchange between leader and follower, and thus reduces a leader's influence. Therefore, transformational instructor-leader behaviours may have a stronger influence on students in smaller class sizes than in larger ones. First, observable charismatic and inspirational behaviours may have more of an impact on student engagement in smaller class sizes than in larger ones because less physical distance may make these behaviours more vivid and impactful. Second, individualised consideration may have a greater impact on student engagement in smaller class sizes than in larger ones because smaller class sizes facilitate deeper relationships and more personalised attention. Finally, intellectual stimulation may have a larger impact on student engagement in smaller class sizes than in larger ones because smaller class sizes allow for greater frequency of interactions for assignments (inclass and/or take-home tasks) and more opportunities for closer social interactions, which can facilitate easier questioning. Given these arguments, the second aim of the present study is to build theory on transformational instructor-leadership by showing 'when' the relationship between such leadership and student engagement is likely to be more strongly manifested (Colquitt and Zapata-Phelan 2007). Hence, we propose the following: 
H4: Class size moderates the relationship between transformational instructor-leadership and student engagement, such that when the class size is smaller, the positive relationship between transformational instructor-leadership and student engagement is stronger than when class size is larger.

\section{Methods}

\section{Participants}

The present study used the same sample examined in Authors (in review), but different measures and analyses were used here ${ }^{2}$. The sample consisted of 183 undergraduate students studying at universities located in England $(\mathrm{n}=169,92.3 \%)$, Scotland $(\mathrm{n}=7,3.8 \%)$, Wales $(\mathrm{n}=$ 6, 3.3\%), and Northern Ireland $(n=1,0.5 \%)$ (i.e., the four countries of the UK). The students were from various faculties including Social Sciences $(n=46,25.1 \%)$, Science $(n=34,18.6 \%)$, Arts and Humanities $(\mathrm{n}=31,16.9 \%)$, Medicine, Dentistry, and Health $(\mathrm{n}=18,9.8 \%)$, Engineering $(\mathrm{n}=16,8.7 \%)$, Law $(\mathrm{n}=9,4.9 \%)$, Film $(\mathrm{n}=7,3.8 \%)$, and other faculties $(\mathrm{n}=20$, $10.9 \%$ ). The sample included 49 males (mean age $=22$ years) and 125 females (mean age $=20$ years).

\section{Materials}

Preceding the questionnaire, brief instructions were given to participants asking them to rate one specific lecturer who taught them in the previous semester. In so doing, participants

\footnotetext{
${ }^{2}$ We intentionally designed two separate papers prior to collecting the data. Each paper had unique research questions and separate theoretical implications that were too expansive for a single paper to address. Although there is a minor overlap between the two papers (i.e., transformational instructorleadership was used to validate a different leadership theory in the other paper), the two papers include substantially unique variables, different results, and different theoretical and practical implications.
} 
were required to (a) choose a lecturer who taught at least half of the classes for the module and (a) recall the grade received for said module. Participants were then asked to provide the lecturer's name, and this name was then used in the upcoming questions.

\section{The Multi-factor Leadership Questionnaire (MLQ)}

We measured transformational instructor-leadership using the Multifactor Leadership Questionnaire (MLQ) (Avolio and Bass 2004), which was adapted to the module context using Pounder's word modifications (Pounder 2008). The MLQ's measure of transformational leadership was composed of 20 items that were represented on a 5 -point continuum $(0=$ not at all; 1 = once in a while; 2 = sometimes; 3 = fairly often; $4=$ frequently, if not always) with higher scores indicating higher transformational instructor-leadership. Five subscales were described for the inventory, including (a) idealised influence (behaviour) (4 items, e.g., '<Name> talked about his/her personal beliefs and value systems while teaching') ( $\alpha=0.63$ ); (b) idealised influence (attributed) (4 items, e.g., '<Name> made me feel proud to be associated with him/her') $(\alpha=0.88)$; (c) inspirational motivation (4 items, e.g., '<Name> talked optimistically about the future') ( $\alpha=0.83$ ); (d) individualised consideration (4 items, e.g., ' $<$ Name $>$ was willing to provide help outside of class') ( $\alpha=0.86)$; and (e) intellectual stimulation (4 items, e.g., ' $<$ Name $>$ listened to different opinions for solving problems arising from the module') $(\alpha=$ 0.76). Overall $\alpha$ for the MLQ was .95.

\section{Student engagement}

We measured student engagement using Rich et al.'s (2010) Job Engagement Questionnaire, which we adapted to the module context. This questionnaire consisted of 18 items that were represented on a 7 -point continuum $(1=$ never; $2=$ rarely; $3=$ occasionally; $4=$ sometimes; $5=$ frequently; $6=$ usually; $7=$ always). The inventory comprised of three subscales, 
including (a) behavioural engagement (6 items, e.g., 'I worked with intensity for $<$ Name $>$ 's module') ( $\alpha=0.95)$; (b) emotional engagement (6 items, e.g., 'I was enthusiastic in $<$ Name $>$ 's module') ( $\alpha=0.96)$; and (c) cognitive engagement (6 items, e.g, 'My mind was focused on $<$ Name $>$ 's module') $(\alpha=0.96)$. Overall $\alpha$ for the student engagement questionnaire was .97 . Academic performance

We measured students' academic performance by students' self-reported grade for the module. Students provided either their actual grade percentage or the range in which their grade percentage lie. We converted all grades percentages to the 7-point scale used for the range question item $(1=$ no grade, $2=1-39,3=40-44,4=45-49,5=50-59,6=60-69,7=70-100)$. Class size

We measured class size by the following item: 'How many students were typically present in $<$ Name>'s module?'. The mean class size was $80.78(S D=98.13)$.

\section{Demographic}

At the end of the questionnaire, participants were asked to provide information regarding their background. Age was measured in years. Gender was coded as ' 0 ' for male and ' 1 ' for female.

\section{Procedures}

We distributed the questionnaire during the second semester of the 2014/2015 academic year, and asked students to rate instructors from the first semester of said academic year. This approach of examining a completed module ensured that (a) students were sufficiently familiar with their instructor and (b) a grade could be provided for the module. Prior to distributing the questionnaire, we conducted a small pilot study to check for understanding of item wordings, and did not identify any problematic issues. After the pilot study, our intention was to collect data 
from at least 200 students in the UK. A sample size of 200 is generally considered appropriate for structural equation modeling (for an overview, see Kline 2011). We restricted our population to UK undergraduate students because the undergraduate grading system is generally consistent between UK universities.

To arrive at our sample, we first sent an email to all undergraduate students at a university located in England. In the email message, participants were given a brief description of the study, a link to an information sheet, a link to the online questionnaire, and details regarding the benefits of taking part. Each participant could opt to receive a free personality evaluation along with entry into a $£ 40$ prize voucher draw. The sample from this survey consisted of 102 students, and thus fell considerably short of our sample size goal. Therefore, we distributed the questionnaire in a second way.

For the second approach, we distributed the questionnaire to students at other UK universities via Qualtrics panel service. Using this service, we sourced 100 undergraduate students from the UK, and each student likely received monetary compensation (less than £5) for completing the survey. Because each of the participants from the Qualtrics panel was likely rewarded with an external incentive, we used an attention filter in the questionnaire to improve the quality of the data, i.e., verify that respondents were reading the questions carefully and following instructions. The attention filter read, 'Please select 'Once in a while' for this statement'. Participants who answered the attention filter question incorrectly were removed from the dataset. Overall, we obtained a sample of 202 participants $^{3}$.

\footnotetext{
${ }^{3}$ For our overall sample, we did not calculate a response rate because we could not identify the number of students to whom the questionnaire was distributed. Specifically, the questionnaire was distributed to (1) a mailing list at a university, for which an exact number of members could not be provided and (2)
} 


\section{Results}

\section{Missing data and statistical assumptions}

Prior to upcoming statistical tests, we accounted for missing data. Missing data was extremely high for 19 of our cases (greater than $30 \%$ ), and thus we used a reduced sample size of 183. Our sample of 183 falls short of Kline's (2011) recommendation of 200. However, Wolf et al. (2013) showed that sample size requirements are smaller when latent factors had more indicator variables, especially when approximately six indicators were used. Given, that four of our six second-order latent factors had five to six indicators, we did not expect our sample size to be particularly problematic.

The assumptions of normality, homoscedasticity, and linearity were examined for all of the study's variables (see Table 1 for a matrix of correlations along with the means and standard deviations for all of the variables). While there appeared to be no issues with respect to homoscedasticity and linearity, many of the variables were non-normal. First, for the 20 MLQ items, all but one of the variables deviated from normality, i.e., 4 of the kurtosis $z$-scores exceeded the critical value of \pm 2.58 , and 18 of the variables were negatively skewed, with skewness $z$-scores ranging from -2.59 to -8.09 . Second, for the 18 student engagement items, 1 of the kurtosis $z$-scores exceeded the critical value of 2.58 , and all 18 variables were negatively skewed, with skewness $z$-scores ranging from -3.08 to -6.22 . Finally, for academic performance and class size, both the kurtosis and skewness $z$-scores exceeded the critical value of \pm 2.58 . Because of these non-normal observed variables in the upcoming models, we used maximum likelihood with the Satorra-Bentler adjustment to the $\chi^{2}$ for non-normality (Tabachnick and size. 
Fidell 2005). We used this estimation procedure via the Lavaan package (Rosseel 2012) for R (R Core Team 2013).

[Insert Table 1 about here]

\section{Factor structures for transformational instructor-leadership and student engagement}

After checking statistical assumptions, we examined the factor structure for both transformational instructor-leadership and student engagement. For transformational instructorleadership, we tested a series of competing models as outlined by Antonakis, Avolio, and Sivasubramaniam (2003). In our study, transformational instructor-leadership was best represented by a 3 -factor model composed of idealised influence attributed/idealised influence behaviour/inspirational motivation, intellectual stimulation, and individualised consideration. For this model, four items were deleted because of poor factor loadings (all <.6). In addition, one residual covariance was estimated based on the modification index along with the similarity between the items' content. The final 16-item model fitted the data fairly well (Satorra-Bentler $\chi^{2}(100)=172.06, p<.05$, Robust CFI $=.95$, RMSEA $\left.=.063\right)$. Also, a second-order factor fitted equally as well.

For student engagement, good support was found for the expected 3-factor model. Still, post hoc model modifications were performed based on (a) the modification indices in combination with theoretical reasoning, and (c) the standardised residual covariance matrix. First, three residual covariances were estimated based on the content of the question items. Second, item 16 appeared problematic because six of its standardised residual covariances exceeded $|2.5|$ (Hair et al. 2009). Therefore, item 16 was deleted. The final model fitted the data very well $\left(\right.$ Satorra-Bentler $\chi^{2}(113)=157.92, p<.05$, Robust CFI $=.98$, RMSEA $\left.=.047\right)$. A second-order factor fitted equally as well. 


\section{Structural model with student engagement as a mediator}

To test student engagement as a mediator, we used structural equation modelling. For the structural model, we followed Anderson and Gerbing's two-step process (Anderson and Gerbing 1988). For the first step, we estimated the measurement model. For the second step, we converted the measurement model into a structural model to test H1 to H3. Hair et al. (2009) reviewed simulation studies, and recommended that when sample size was less than 250 and the number of indicator variables exceeded 30, significant $p$-values were to be expected for $\chi^{2}, \mathrm{CFI}$ should be above .92 , and RMSEA should be less than .08 . Following these recommendations, the structural model showed good model fit (Satorra-Bentler $\chi^{2}(582)=849.71, p<.05$, Robust $\mathrm{CFI}=.94, \mathrm{RMSEA}=.051) . \mathrm{H} 1$ was supported because transformational instructor-leadership shared a strong and positive significant relationship with student engagement $(\gamma=0.78, p<$ .001). H2 was also supported because student engagement shared a positive significant relationship with academic performance $(\beta=0.24, p<.01)$. Neither age nor gender was significant in the model.

To check the mediating effect in the structural model, the first step was to establish the significant relationships between the constructs. This analysis was conducted by checking (a) the direct unmediated relationship between transformational instructor-leadership and academic performance $(\Phi=0.23, p<.05)$, (b) the relationship between student engagement and transformational instructor-leadership $(\Phi=0.79, p<.001)$, and (c) the relationship between student engagement and academic performance $(\Phi=0.23, p<.01)$ (Hair et al. 2009). We then assessed the level of mediation by adding a direct unmediated path from transformational instructor-leadership to academic performance. This direct unmediated path was not significant, and did not significantly improve the fit of the model (Satorra-Bentler $\chi_{\text {difference }}^{2}[1]=1.14, p>$ 
0.05). Therefore, student engagement was a full mediator in the relationship between transformational instructor-leadership and students' academic performance, and thus H3 was supported. The strength of the indirect relationship between transformational instructorleadership and academic performance was $0.19(p<.01)$.

\section{Structural model with student engagement as a mediator and class size as a moderator}

To test the moderation effect of class size on the relationship between transformational instructor-leadership and student engagement, we used the residual centering approach as outlined by Steinmetz, Davidov, and Schmidt (2011). The residual centering approach is superior to conventional regression approaches because it (a) controls for measurement error and (b) eliminates multicollinearity problems (Steinmetz, Davidov, and Schmidt 2011). The residual centering approach consists of two steps. In the first step, we created a composite variable for each of the three transformational instructor-leadership constructs, and multiplied each of these three constructs by class size. Then, each of the three resulting product variables were regressed on charisma, individualised consideration, intellectual stimulation, and class size. In the second step, the residuals from each of the three regression analyses were indicators of a latent interaction variable. Again, given the complexity of the model and the sample size, the resulting model fitted fairly well to the data (Satorra-Bentler $\chi^{2}(724)=1007.15, p<.05$, Robust CFI $=$ .93$, RMSEA $=.048)($ Hair et al. 2009). The interaction effect was negative as expected, but not significant $(\gamma=-0.03, p>.05)$. Therefore, $\mathrm{H} 4$ was not supported. The final structural model is shown in Figure 1.

[Insert Figure 1 about here] 


\section{Discussion}

The findings from our empirical model contribute to transformational instructorleadership research. Previous transformational instructor-leadership studies primarily focused on the direct association between transformational instructor-leadership and student outcomes, ignoring the processes underlying these associations (Balwant 2016). The present study contributes to this body of research by showing that student engagement is a mechanism in the relationship between transformational instructor-leadership and academic performance. In fact, student engagement appears to be a key mechanism in the stated relationship given the strength of the indirect association (.19 in the present study) in comparison to the strength of a direct association in previous research (.19 in the meta-analysis by Balwant 2016). Overall, we contribute a moderate level of theory building by showing 'how' and explaining 'why' student engagement is a mechanism in the transformational instructor-leadership to academic performance relationship. By identifying and investigating this mechanism, the present study shifts transformational instructor-leadership research towards a more mature level.

Another contribution of this study is that we add to educational research on student engagement. Using the conceptualisation offered by Balwant (2017b), we extend previous research on student engagement in higher education by measuring the full three-dimensional concept as opposed to one or two dimensions as was examined in previous studies (Fredricks, Blumenfeld, and Paris 2004). Our study provides strong empirical support for either (a) a threefactor structure representing emotional, behavioural, and cognitive engagement or (b) a single higher-order construct representing student engagement.

Finally, the lack of empirical support for structural distance as a moderator raises certain questions. Even though class size is regarded as an indicator of distance, perhaps what is needed is a measure of students' perceptions of structural distance. Specifically, instructors may create 
students' perceptions of structural distance regardless of class size. For instance, an instructor in a large class may walk around the classroom, use nametags to call students by name, and use touch appropriately, and thus may be perceived as physically close even in a large class (Neuliep 1997). Conversely, an instructor in a small class may be perceived as physically distant if said instructor stands behind a podium and talks to students without encouraging any two-way communication in the instructor-student relationship. Perceptions of distance may also vary depending on the layout of facilities, e.g., auditoriums, seminar rooms, and cabaret-style set ups. Another possible reason for our nonsignificant finding is the role of distance in leadership. Even though leadership researchers suggest that distance is a neutraliser of leadership, i.e., distance reduces leader effects on followers, distance may instead be (a) a condition for charismatic leadership and (b) a moderator of which type of charismatic leadership develops (Antonakis and Atwater 2002). In the next section, we offer suggestions for future research on distance in leadership research.

\section{Limitations and suggestions for future research}

Our theoretical contributions should be considered in light of certain limitations. One limitation of the present study is that we rely on cross-sectional data to draw our conclusions. Cross-sectional data allows for causal inferences rather than causal conclusions. Specifically, by using cross-sectional data we cannot show that transformational instructor-leadership causes students to become engaged, and that engagement causes students to achieve higher grades. It is possible that reverse relationships are true, e.g., highly engaged students cause instructors to use more transformational leader behaviours (Skinner and Belmont 1993). Therefore, future research requires experimental designs and longitudinal studies to confirm the direction of causality. 
Another limitation of the present study is that the use of self-report instruments to measure transformational instructor-leadership, student engagement, and academic performance means that our findings can be affected by common method bias. Although the effects of common method bias are not usually strong enough to invalidate research findings, it can be a cause for concern (Doty and Glick 1998). To minimise the effects of common method bias, future research should consider (a) obtaining predictor, mediator, and outcome variables from different sources (Podsakoff et al. 2003), (b) employing a marker variable technique (Williams, Hartman, and Cavazotte 2010), and/or (c) directly measuring and controlling for potential causes of method bias, e.g., controlling for social desirability, positive affectivity, or negative affectivity (Podsakoff et al. 2003).

A further limitation of using self-report measures of leadership is that they can create challenges for the accuracy of leadership ratings. Hansbrough, Lord, and Schyns (2015) explain that follower ratings of leadership are prone to numerous individual biases, e.g., personality, affectivity, needs and motives, and attribution styles; psychological biases, e.g., stereotyping, perceived similarity, liking, and mood; and contextual biases, e.g., leader individual differences, distance, national culture, and research methods. To minimise these biases in future instructorleadership studies, numerous techniques can be employed, including the training of studentraters; the use of more explicit and accurate instructions; use of scripts, events, and/or critical incidents in framing questions; and controlling for individual differences (Hansbrough, Lord, and Schyns 2015).

A final limitation of this study is that it was conducted in one cultural context, i.e., the UK. As such, the strength of the relationships in our model needs to be confirmed across cultures. For instance, the UK culture may emphasise more supportive type leader behaviours, 
e.g., consideration, whereas the US culture may favor more charismatic behaviour (AlimoMetcalfe and Alban-Metcalfe 2005). This notion is in line with the Global Leadership and Organisational Behavior Effectiveness (GLOBE) research findings, which suggest that different cultures have different implicit theories about outstanding and acceptable leaders (Javidan et al. 2006).

Future research should also consider a more comprehensive measure of distance than in the present study. In our study, we used one indicator of structural distance, i.e., class size. However, as stated earlier, structural distance may vary depending on students' perceptions of their interactions with their instructor. Hence, a scale may need to be developed to better capture the concept of structural distance as we have outlined, i.e., questions that directly measure physical design, opportunity to interact, spatial distance, and span of management. Furthermore, Antonakis and Atwater (2002) explain that distance consists of not only structural (or physical) distance but also psychological (or social) distance and perceived interaction frequency. Psychological distance refers to 'perceived differences in status, rank, authority, social standing, and power' (Antonakis and Atwater 2002, 682). Perceived frequency of interaction refers to 'the perceived degree to which leaders interact with their followers' (Antonakis and Atwater 2002, 686). Both forms of distance are likely to exist in instructor-student relationships, and should be examined together with structural distance in order to provide a better representation of distance.

Finally, future research should consider the role of leader distance for other instructorleadership behaviours. With respect to instructor-leadership, researchers have investigated initiating structure and consideration (Dawson, Messe, and Phillips 1972; Baba and Ace 1989), ethical leadership (Goodyear, Crego, and Johnston 1992), transactional leadership (Ojode, Walumbwa, and Kuchinke 1999; Walumbwa, Wu, and Ojode 2004; Pounder 2008) and 
destructive leadership (Balwant 2017a) in higher education classroom contexts. It is worth examining whether leader distance can moderate the relationship between these instructor-leader behaviours and students' outcomes. For instance, supportive leader behaviours like consideration or destructive leader behaviours like hostility may be more impactful when the leader is close to followers. However, task oriented leader behaviours typically captured by initiating structure and transactional leadership, e.g., setting goals and expectations and/or scheduling work, may require a certain degree of distance. That is, followers may more likely follow rules and regulations, and accept standards of performance if they perceive that the leader is of higher status or power (psychological distance).

\section{Practical implications and conclusion}

We offer a few practical recommendations based on the findings in the present study. First, a major practical implication of our research is that it can be used as a basis for training and developing higher education instructors in the UK. The training and development of instructorleadership can be described in four phases, including assessment, design, implementation, and evaluation (DeSimone and Werner 2006). In the needs assessment phase, teaching performance gaps can be identified using student feedback questionnaires, discussions with heads of departments, and/or the use of trained observers. Once a teaching performance gap has been identified, the programme can be designed and implemented by following key activities. First, objectives should be set and these can be based on the transformational instructor-leadership behaviours identified in the present paper, e.g., an individualised consideration objective can be, 'Be able to provide help outside of class'. Second, the trainer or vendor can be selected by using the institution's own staff and/or external trainers. Third, training methods and media can include the discussion method, behaviour role modelling, case discussion, and/or simulations all 
of which can be delivered through short term interventions or workshops (Yukl 2006). Also, given the time pressures many instructors face, self-training through videos or interactive computer programmes can be used as a substitute for formal training (Yukl 2006), e.g., a video on inspirational motivation can show an instructor talking optimistically about the future. Videos can even highlight the students' point of view showing how they become engaged in response to transformational instructor-leadership behaviours. After design and implementation, the final phase is the evaluation of the training programme. For this phase, Kirkpatrick's (2004) model can be used to judge trainees' reaction, learning, behaviour, and results.

For training and development, it is often unrealistic to expect that all instructors can adopt the varied number of transformational leadership behaviours. A reality that has to be faced is the teaching staff's breadth of their repertoire of teaching methods (Bourner 1997). According to Bourner $(1997,348)$, '[i]f the teaching repertoire of academic staff is limited to only a few of the methods then that is the real choice available to us'. Therefore, research that advocates training programmes geared towards the development of numerous behaviours and methods, may not only be impractical but may also represent a waste of resources. Instead of this scattershot approach, what is needed is for performance feedback to feed directly into the needs assessment phase of training and development.

For performance feedback, most higher education institutions use some form of teaching evaluation instrument. The MLQ can be incorporated into a subset of all module evaluations sent to students because the instrument is not freely available. However, the additional expense of utilizing the MLQ may be worthwhile because of the strong relationships between transformational instructor-leadership and student engagement. One limitation of this approach is 
that modules with shared teaching responsibilities cannot be evaluated unless one instructor is the primary module coordinator, and also teaches the majority of classes.

In addition to training and development, transformational instructor-leaders can be identified when hiring instructors. During the selection process, instructors can be screened using psychometric assessments. Psychometric assessments can be used to measure personality traits indicative of transformational instructor-leaders such as extraversion and agreeableness (Judge and Bono 2000).

In conclusion, the present study extends transformational instructor-leadership research by showing that student engagement is a key mechanism through which such leadership is related to students' academic performance. Even though our findings do not support the hypothesised moderation effect of structural distance, we outline recommendations for future research on distance as a moderator. We encourage future research that can further develop theory on transformational instructor-leadership by showing how the inclusion of theoretically relevant concepts can alter and/or enhance our understanding of the causal maps between transformational instructor-leadership and student outcomes.

$$
\text { Word count }=7,559 \text { (excl. references })
$$

The authors have no conflicts of interest to disclose.

\section{References}

Alimo-Metcalfe, B., and J. Alban-Metcalfe. 2005. "Leadership: Time for a New Direction?" Leadership 1 (1): 51-71. doi:10.1177/1742715005049351.

Anderson, James, and David W. Gerbing. 1988. "Structural Equation Modeling in Practice: A Review and Recommended Two-Step Approach.” Psychological Bulletin 103 (3): 411423.

Antonakis, John, and Leanne Atwater. 2002. "Leader Distance: A Review and a Proposed Theory." The Leadership Quarterly 13 (6): 673-704. doi:10.1016/S1048-9843(02)001558 . 
Antonakis, John, B.J. Avolio, and Nagaraj Sivasubramaniam. 2003. "Context and Leadership: An Examination of the Nine-Factor Full-Range Leadership Theory Using the Multifactor Leadership Questionnaire." The Leadership Quarterly 14 (3): 261-295. doi:10.1016/S1048-9843(03)00030-4.

Avolio, B.J., and B.M. Bass. 2004. "Multifactor Leadership Questionnaire: Manual and Sample Set." Mind Garden, Inc.

Baba, Vishwanath V., and Merle E. Ace. 1989. "Serendipity in Leadership: Initiating Structure and Consideration in the Classroom." Human Relations 42 (6): 509-525. doi:10.1177/001872678904200603.

Babcock-Roberson, M. E., and O. J. Strickland. 2010. “The Relationship between Charismatic Leadership, Work Engagement, and Organizational Citizenship Behaviors." Journal of Psychology 144 (3): 313. doi:10.1080/00223981003648336.

Balwant, Paul T. 2016. "Transformational Instructor-Leadership in Higher Education Teaching: A Meta-Analytic Review and Research Agenda.” Journal of Leadership Studies 9 (4): 20-42. doi:10.1002/jls.21423.

Balwant, Paul T. 2017a. "The Dark Side of Teaching: Destructive Instructor Leadership and Its Association with Students' Affect, Behaviour, and Cognition." International Journal of Leadership in Education 20 (5): 577-604. doi:10.1080/13603124.2015.1112432.

Balwant, Paul T. 2017b. "The Meaning of Student Engagement and Disengagement in the Classroom Context: Lessons from Organisational Behaviour." Journal of Further and Higher Education 0 (0): 1-13. doi:10.1080/0309877X.2017.1281887.

Bass, B.M. 1985. Leadership and Performance beyond Expectations. New York: London: Free Press.

Bass, B.M. 1990a. "From Transactional to Transformational Leadership: Learning to Share the Vision." Organizational Dynamics 18 (3): 19-31. doi:10.1016/0090-2616(90)90061-S.

Bass, B.M. 1990b. Bass \& Stogdill's Handbook of Leadership: Theory, Research \& Managerial Applications. 3 Sub edition. New York : London: Free Press.

Bass, B.M. 1997. "Does the Transactional-transformational Leadership Paradigm Transcend Organizational and National Boundaries?" American Psychologist 52 (2): 130-139. doi:10.1037/0003-066X.52.2.130.

Bolkan, San, and Alan K. Goodboy. 2009. "Transformational Leadership in the Classroom: Fostering Student Learning, Student Participation, and Teacher Credibility.” Journal of Instructional Psychology 36 (4): 296-306.

Bono, Joyce E., Hannah Jackson Foldes, Gregory Vinson, and John P. Muros. 2007. "Workplace Emotions: The Role of Supervision and Leadership." Journal of Applied Psychology 92 (5): 1357-1367. doi:10.1037/0021-9010.92.5.1357.

Bourner, Tom. 1997. "Teaching Methods for Learning Outcomes.” Education + Training 39 (9): 344-348. doi:10.1108/00400919710192377.

Bruininks, Patricia, and Bertram F. Malle. 2005. "Distinguishing Hope from Optimism and Related Affective States." Motivation and Emotion 29 (4): 324-352. doi:10.1007/s11031006-9010-4.

Burch, Gerald F., Jana J. Burch, and John Womble. 2017. "Student Engagement: An Empirical Analysis of the Effects of Implementing Mandatory Web-Based Learning Systems." Organization Management Journal 14 (June): 116-125. doi:10.1080/15416518.2017.1325349. 
Burch, Gerald F., Nathan A. Heller, Jana J. Burch, Rusty Freed, and Steve A. Steed. 2015. "Student Engagement: Developing a Conceptual Framework and Survey Instrument." Journal of Education for Business 90 (March): 224-229. doi:10.1080/08832323.2015.1019821.

Colquitt, Jason A., and Cindy P. Zapata-Phelan. 2007. "Trends in Theory Building and Theory Testing: A Five-Decade Study of the Academy of Management Journal." Academy of Management Journal 50 (6): 1281-1303. doi:10.5465/AMJ.2007.28165855.

Conger, Jay A., and Rabindra N. Kanungo. 1987. "Toward a Behavioral Theory of Charismatic Leadership in Organizational Settings." The Academy of Management Review 12 (4): 637. doi:10.2307/258069.

Dawson, Jack E., Lawrence A. Messe, and James L. Phillips. 1972. "Effect of Instructor-Leader Behavior on Student Performance." Journal of Applied Psychology 56 (5): 369-376. doi: $10.1037 / \mathrm{h} 0033436$.

DeSimone, Randy L., and Jon M. Werner. 2006. Human Resource Development. 4th edition. Ohio, U.S.: SouthWestern.

Doty, D. Harold, and William H. Glick. 1998. "Common Methods Bias: Does Common Methods Variance Really Bias Results?” Organizational Research Methods 1 (4): 374-406. doi:10.1177/109442819814002.

Fredricks, J. A., P. C. Blumenfeld, and A. H. Paris. 2004. "School Engagement: Potential of the Concept, State of the Evidence." Review of Educational Research 74 (1): 59-109.

Gill, A., Rajendra Tibrewala, Abram Poczter, Nahum Biger, Harvinder Mand, Suraj Sharma, and Karamjit Dhande. 2010. "Effects of Transformational Leadership on Student Educational Satisfaction and Student Stress.” The Open Education Journal 3: 1-9. doi:10.2174/1874920801003010001.

Goodyear, Rodney K., Clyde A. Crego, and Michael W. Johnston. 1992. "Ethical Issues in the Supervision of Student Research: A Study of Critical Incidents." Professional Psychology: Research \& Practice 23 (3): 203-210.

Hair, Joseph F. Jr., William C. Black, Barry J. Babin, and Rolph Anderson. 2009. Multivariate Data Analysis. 7th ed. Prentice Hall.

Hansbrough, Tiffany Keller, Robert G. Lord, and Birgit Schyns. 2015. "Reconsidering the Accuracy of Follower Leadership Ratings.” The Leadership Quarterly 26 (2): 220-237. doi:10.1016/j.leaqua.2014.11.006.

Harrison, J. 2011. "Instructor Transformational Leadership and Student Outcomes.” Emerging Leadership Journeys 4 (1): 82-136.

Harvey, Steve, Martin Royal, and Dale Stout. 2003. "Instructor's Transformational Leadership: University Student Attitudes and Ratings.” Psychological Reports 92 (2). doi:10.2466/PR0.92.2.395-402.

Heikkilä, A., and K. Lonka. 2006. "Studying in Higher Education: Students' Approaches to Learning, Self- regulation, and Cognitive Strategies." Studies in Higher Education 31 (1): 99-117. doi:10.1080/03075070500392433.

Hoon Song, Ji, Judith A. Kolb, Ung Hee Lee, and Hye Kyoung Kim. 2012. "Role of Transformational Leadership in Effective Organizational Knowledge Creation Practices: Mediating Effects of Employees' Work Engagement.” Human Resource Development Quarterly 23 (1): 65-101. doi:10.1002/hrdq.21120. 
House, R.J. 1976. “A 1976 Theory of Charismatic Leadership. Working Paper Series 76-06.” In . http://www.eric.ed.gov/ERICWebPortal/contentdelivery/servlet/ERICServlet?accno=ED 133827.

Jacquart, P., and J. Antonakis. 2015. "When Does Charisma Matter for Top-Level Leaders? Effect of Attributional Ambiguity." Academy of Management Journal 58 (4): 1051-1074. doi:10.5465/amj.2012.0831.

Javidan, Mansour, Peter W. Dorfman, Mary Sully de Luque, and Robert J. House. 2006. "In the Eye of the Beholder: Cross Cultural Lessons in Leadership from Project GLOBE." Academy of Management Perspectives 20 (1): 67-90.

Jimerson, S., E. Campos, and J. Greif. 2003. "Toward an Understanding of Definitions and Measures of School Engagement and Related Terms." The California School Psychologist 8: 7-27.

Judge, T A, and J E Bono. 2000. "Five-Factor Model of Personality and Transformational Leadership." Journal of Applied Psychology 85 (5): 751-765.

Kahu, E. R. 2013. "Framing Student Engagement in Higher Education." Studies in Higher Education 38 (5): 758-773. doi:10.1080/03075079.2011.598505.

Kendall, K. Denise, and Elisabeth E. Schussler. 2012. "Does Instructor Type Matter? Undergraduate Student Perception of Graduate Teaching Assistants and Professors." CBE Life Sciences Education 11 (2): 187-199. doi:10.1187/cbe.11-10-0091.

Kezar, A. J., and J. Kinzie. 2006. "Examining the Ways Institutions Create Student Engagement: The Role of Mission." Journal of College Student Development 47 (2): 149-172. doi:10.1353/csd.2006.0018.

Kimiecik, J. C., and A. T. Harris. 1996. "What Is Enjoyment? A Conceptual/Definitional Analysis with Implications for Sport and Exercise Psychology." Journal of Sport \& Exercise Psychology 18 (3): 247-263.

Kirkpatrick, D. 2004. "A T+D Classic: How to Start an Objective Evaluation of Your Training Program.” $T+D 58$ (5): 1-3.

Kline, Rex B. 2011. Principles and Practice of Structural Equation Modeling. New York: Guilford Press.

Kopperud, Karoline Hofslett, Øyvind Martinsen, and Sut I. Wong Humborstad. 2014. "Engaging Leaders in the Eyes of the Beholder on the Relationship between Transformational Leadership, Work Engagement, Service Climate, and Self-other Agreement." Journal of Leadership \& Organizational Studies 21 (1): 29-42. doi:10.1177/1548051813475666.

Kovjanic, Snjezana, Sebastian C. Schuh, and Klaus Jonas. 2013. “Transformational Leadership and Performance: An Experimental Investigation of the Mediating Effects of Basic Needs Satisfaction and Work Engagement." Journal of Occupational and Organizational Psychology 86 (4): 543-555. doi:10.1111/joop.12022.

Macey, W., and B. Schneider. 2008. "The Meaning of Employee Engagement." Industrial and Organizational Psychology 1 (3): 3-30. doi:10.1111/j.1754-9434.2007.0002.x.

Napier, Barbara J., and Gerald R. Ferris. 1993. "Distance in Organizations." Human Resource Management Review 3 (4): 321-357. doi:10.1016/1053-4822(93)90004-N.

Neuliep, James W. 1997. "A Cross-Cultural Comparison of Teacher Immediacy in American and Japanese College Classrooms.” Communication Research 24 (4): 431-451. doi:10.1177/009365097024004006.

Nystrand, M., and A. Gamoran. 1991. "Instructional Discourse, Student Engagement, and Literature Achievement.” Research in the Teaching of English 25 (3): 261-290. 
Ojode, L, O Walumbwa, and P Kuchinke. 1999. "Developing Human Capital for the Evolving Work Environment: Transactional and Transformational Leadership within Instructional Setting." In . Lincoln.

Pekrun, Reinhard, A. J. Elliot, and M. A. Maier. 2009. “Achievement Goals and Achievement Emotions: Testing a Model of Their Joint Relations with Academic Performance." Journal of Educational Psychology 101 (1): 115-135. doi:10.1037/a0013383.

Pekrun, Reinhard, Thomas Goetz, Wolfram Titz, and Raymond P. Perry. 2002. "Academic Emotions in Students' Self-Regulated Learning and Achievement: A Program of Qualitative and Quantitative Research.” Educational Psychologist 37 (2): 91-105. doi:10.1207/S15326985EP3702_4.

Peters, Janet. 2014. "Transformational Teachership: How Principles of Transformational Leadership Foster Student Outcomes." Unpublished doctoral dissertation, Colorado, US: Colorado State University.

Plant, E. Ashby, K. Anders Ericsson, Len Hill, and Kia Asberg. 2005. "Why Study Time Does Not Predict Grade Point Average across College Students: Implications of Deliberate Practice for Academic Performance.” Contemporary Educational Psychology 30 (1): 96116. doi:10.1016/j.cedpsych.2004.06.001.

Podsakoff, Philip M., Scott B. MacKenzie, Jeong-Yeon Lee, and Nathan P. Podsakoff. 2003. "Common Method Biases in Behavioral Research: A Critical Review of the Literature and Recommended Remedies.” Journal of Applied Psychology 88 (5): 879-903. doi:10.1037/0021-9010.88.5.879.

Pounder, James S. 2008. "Full-Range Classroom Leadership: Implications for the CrossOrganizational and Cross-Cultural Applicability of the Transformational-Transactional Paradigm." Leadership 4 (2): 115-135. doi:10.1177/1742715008089634.

R Core Team. 2013. R: A Language and Environment for Statistical Computing. Vienna, Austria: R Foundation for Statistical Computing. http://www.R-project.org/.

Reinsch, Roger, and Jacob R. Wambsganss. 1994. "Class Participation: How It Affects Results on Examinations.” Journal of Education for Business 70 (1): 33-37. doi:10.1080/08832323.1994.10117721.

Rich, B. L., J. A. Lepine, and E. R. Crawford. 2010. “Job Engagement: Antecedents and Effects on Job Performance.” Academy of Management Journal 53 (3): 617-635. doi:10.5465/AMJ.2010.51468988.

Rosseel, Yves. 2012. “Lavaan: An R Package for Structural Equation Modeling.” Journal of Statistical Software 48 (2): 1-36.

Salanova, Marisa, Sonia Agut, and José María Peiró. 2005. "Linking Organizational Resources and Work Engagement to Employee Performance and Customer Loyalty: The Mediation of Service Climate." Journal of Applied Psychology 90 (6): 1217-1227. doi:10.1037/0021-9010.90.6.1217.

Schaufeli, W. B., I. M. Martínez, A. M. Pinto, M. Salanova, and A. B. Bakker. 2002. "Burnout and Engagement in University Students: A Cross-National Study." Journal of CrossCultural Psychology 33 (5): 464-481. doi:10.1177/0022022102033005003.

Silva, Diane Yendol, Belinda Gimbert, and James Nolan. 2000. "Sliding the Doors: Locking and Unlocking Possibilities for Teacher Leadership.” Teachers College Record 102 (4): 779804. 
Skinner, Ellen A., and Michael J. Belmont. 1993. "Motivation in the Classroom: Reciprocal Effects of Teacher Behavior and Student Engagement across the School Year." Journal of Educational Psychology 85 (4): 571-581. doi:10.1037/0022-0663.85.4.571.

Steinmetz, Holger, Eldad Davidov, and Peter Schmidt. 2011. "Three Approaches to Estimate Latent Interaction Effects: Intention and Perceived Behavioral Control in the Theory of Planned Behavior." Methodological Innovations Online 6 (1): 95-110. doi:10.4256/mio.2010.0030.

Tabachnick, Barbara G., and Linda S. Fidell. 2005. Using Multivariate Statistics. 5th ed. Pearson Education.

Tews, Michael J., Kathy Jackson, Crystal Ramsay, and John W. Michel. 2015. "Fun in the College Classroom: Examining Its Nature and Relationship with Student Engagement." College Teaching 63 (January): 16-26. doi:10.1080/87567555.2014.972318.

Torenbeek, Marjolein, Ellen Jansen, and Adriaan Hofman. 2010. "The Effect of the Fit between Secondary and University Education on First- year Student Achievement." Studies in Higher Education 35 (6): 659-675. doi:10.1080/03075070903222625.

Torenbeek, Marjolein, Ellen Jansen, and Cor Suhre. 2013. 'Predicting Undergraduates' Academic Achievement: The Role of the Curriculum, Time Investment and SelfRegulated Learning." Studies in Higher Education 38 (9): 1393-1406. doi:10.1080/03075079.2011.640996.

Trowler, V., and P. Trowler. 2010. "Student Engagement Evidence Summary.” Higher Education Academy. http://www.heacademy.ac.uk/assets/documents/studentengagement/StudentEngagementE videnceSummary.pdf.

Vincent-Hoper, Sylvie, Clara Muser, and Monique Janneck. 2012. "Transformational Leadership, Work Engagement, and Occupational Success." Career Development International 17 (7): 663-682. doi:http://dx.doi.org/10.1108/13620431211283805.

Walumbwa, Fred O., Cindy Wu, and Lucy A. Ojode. 2004. "Gender and Instructional Outcomes: The Mediating Role of Leadership Style.” Journal of Management Development 23 (2): 124-140. doi:10.1108/02621710410517229.

Williams, Larry J., Nathan Hartman, and Flavia Cavazotte. 2010. "Method Variance and Marker Variables: A Review and Comprehensive CFA Marker Technique.” Organizational Research Methods 13 (3): 477-514. doi:10.1177/1094428110366036.

Wolf, Erika J., Kelly M. Harrington, Shaunna L. Clark, and Mark W. Miller. 2013. "Sample Size Requirements for Structural Equation Models: An Evaluation of Power, Bias, and Solution Propriety." Educational and Psychological Measurement 73 (6): 913-934. doi:10.1177/0013164413495237.

Yammarino, Francis J, and B.M. Bass. 1988. Long-Term Forecasting of Transformational Leadership and Its Effects among Naval Officers: Some Preliminary Findings. Center for Leadership Studies. http://www.dtic.mil/dtic/tr/fulltext/u2/a204110.pdf.

Yukl, Gary. 2006. Leadership in Organizations. 6th ed. New Jersey: Prentice Hall. 


\section{Appendices}

Table 1

Summary of Intercorrelations, Means, and Standard Deviations for the Scores of Transformational Instructor-Leadership, Student Engagement, Academic Performance and Class Size

\begin{tabular}{llllrr}
\hline Variables & 1 & 2 & 3 & Mean & SD \\
\hline 1. Transformational leadership & & & & 3.85 & .80 \\
2. Student engagement & $.71^{* * *}$ & & & 5.34 & 1.22 \\
3. Academic performance & $.31^{* *}$ & $.31^{* *}$ & & 4.78 & 1.04 \\
4. Class size & -.02 & -.08 & .04 & 80.78 & 98.13 \\
\hline
\end{tabular}

Note.

** Correlation is significant at the 0.01 level (2-tailed). 
Figure 1. Structural model of the relationships between transformational instructor-leadership, student engagement, structural distance, and academic performance. Standardised parameter estimates. Indicator variables and error variances excluded for ease in readability. Dashed lines indicate non-significant relationships. All first-order latent variable indicators were significant $(p$ $<.001) . * * * p<.001 . * * p<.01$. 